\title{
Análise do processo de trabalho dos agentes de vigilância ambiental do município de Olinda, Pernambuco
}

\author{
Analysis of the work process of environmental surveillance agents \\ in the city of Olinda, Pernambuco State
}

Fernando Castim Pimentel ${ }^{1}$

Paulette Cavalcanti deAlbuquerque ${ }^{1}$

Raquel Moura LinsAcioli ${ }^{2}$

\footnotetext{
${ }^{1}$ Centro de Pesquisas Aggeu M agalhães, Fundação O swaldo Cruz. Av.

Professor M oraes Rego $s / \mathrm{n}$, CidadeU niversitária. 50670-420 Recife PE.

nandocastim@yahoo.com.br

2 UniversidadeFederal de

Pernambuco.
}

This work aimed to analyze the coverage of the Program of Environmental Surveillancein H ealth in the city of Olinda, Pernambuco State and the factors that interfered in not achieving the number of properties established by the $\mathrm{N}$ ational Program of D engue's Control to be visited by the environmental surveillance agents, among them the number of absences and the number of properties worked daily. For theaccomplishment of thestudy, a database was prepared with a list of agents that worked in the year of 2006, consi dering the number of absences, medical licenses, vacations and the number of worked properties. The results showed that the number of properties worked by the agents per day had a larger influence in the low income presented in the year of 2006 when compared to the number of their absences. The high number of closed propertiesand refusals, lack of materials, constant training courses and agent demands for other health actions were some factors that contributed to the low productivity of the agents. Therefore, it is necessary a change in the work process of the environmental surveillance agents, as well as a more discerning and constant evaluation of their activities so that it is possible to reach the established goals. Key words Public health, Environmental health, Environmental surveillance, $\mathrm{H}$ ealth personnel
Resumo Este trabalho teve como objetivo analisar a cobertura do Programa de Vigilância Ambiental em Saúde no município de Olinda e os aspectos que podem ter interferido no fato de não se ter visitado o número de imóveis estabel eci dos pelo Programa Nacional de Controle da Dengue, dentre eles o número de faltas dos agentes de vigilância ambiental e a quantidade de imóveis trabalhados diariamente. Para a realização do estudo, criou-se um banco de dados com a relação de todos os agentes que trabalharam no ano de2006, levando-se em consideração o número de faltas, licenças médicas, férias, além do número de imóveis trabalhados. Os resultados mostraram que 0 número de imóveis trabalhados pelos agentes por dia teve uma maior influência no baixo rendimento apresentado no ano de 2006, quando comparado ao número desuas faltas. D entre os fatores que contribuíram para uma média abaixo do esperado estão o alto número de pendências (imóveis fechados e recusas), a falta de materiais, os constantes cursos de capacitação ea demanda dos agentes para outras ações de saúde. Portanto, conclui-se ser necessária uma mudança no processo de trabalho dos agentes de vigilância ambiental, além de uma avaliação mais criteriosa e constante de suas atividades para que seja possí vel atingi r as metas predeterminadas. Palavras-chave Saúdepública, Saúdeambiental, Vigilância ambiental, Pessoal de saúde 
Introdução

A pesar da preocupação com o ambiente já existir há al guns anos, a incorporação da vigilância ambiental no campo das políticas públicas de saúde éuma demanda relativamente recente no Brasil e em processo de estruturação. Em 1990, já se demonstrava a intenção de intervir nos fatores de risco ambientaisatravés da Lei $n^{\circ} 8.080$, queinclui como campo de atuação do SUS a "colaboração na proteção do meio ambiente", bem como o controle da água para consumo humano e de substâncias tóxicas e radioativas. Entretanto, com a regulamentação do Sistema N acional de VigilânciaAmbiental em Saúde (SINVAS), através da Instrução Normativa $n^{\circ} 1$ do M inistério da Saúde, de 25 desetembro de 2001, que definiu competênciasno âmbito federal, estadual emunicipal, coube aos municípios a execução dos programas de Vigilância Ambiental em Saúde, em consonância com as demais esferas de governo ${ }^{1}$.

A Fundação Nacional de Saúde (FUNASA) define a vigilância ambiental como um conjunto de ações que proporciona o conhecimento, a detecção ou prevenção de qualquer mudança nos fatores determinantes e condicionantes do meio ambiente que interferem na saúdehumana, com a finalidade de recomendar e adotar as medidas de prevenção e controle dos fatores de riscos e das doen ças ou agravos'. Entretanto, controlar os fatores ambientais que interferem no processo saúde-doença não é tarefa simples, visto que grande parte da população sofre com diversas situações, em especial, relativas a vetores, reservatórios e hospedeiros, animais peçonhentos, qualidade da água para consumo humano, contaminantes ambientais, de sastres naturais, acidentes com produtos perigosos, saneamento básico, disposição de dejetos humanos e animais e condições habitacionais ${ }^{3}$.

Para isso, o SI NVAS tem como principal protagonista de suas ações 0 agente de combate às endemias, que tem como atribuições o exercício de atividades de vigilância, prevenção e controle de doenças e promoção da saúde, desenvolvidas em conformidade com as diretrizes do SU S e sob supervisão do gestor decada ente federado ${ }^{4}$. Esse profissional de saúde surge como uma peça fundamental no processo de estruturação das ações de saúde ambiental dos municípios, em que os mesmos passaram a ser chamados agentes de saúde ambiental (ASA) em Recife, ou agentes de vigilância ambiental (AVA), no caso de Olinda. $\mathrm{Na}$ linha de frente do programa, esse profissional possui uma grande responsabilidade sanitá- ria, executando ações de vigilância ambiental, controle, educação e informações dirigidas ao meio físico-biológico (fauna, água, solo) e sociocultural (habitação) ${ }^{5,6}$.

Os agentes desenvolvem seu trabalho em nível local, em que cada um se responsabiliza por um território específico, visitando casas, espaços públicos, parques e edificações. Segundo Lyra7, os agentes de saúde ambiental da cidade do Recifeidentificam pontos estratégicos, dentro desuas áreas, que necessitam de melhorias. Os agentes desempenham um papel fundamental no sucesso do programa, já que servem de ligação entre a comunidade e o governo. Em muitas localidades, eles são os únicos representantes governamentais que os moradores vêem com frequência, estando presentes seis horas por dia, cinco dias por semana. No sentido inverso, os agentes representam uma forma do governo prestar contas à população, pois acompanham 0 atendimento às queixas dos cidadãos. Servem ainda para transmitir informações e desenvolver ações educativas de interesse do governo municipal e para ajudar na implementação de políticas públicas em nível local. Vale destacar que a distribuição dosASA em cada território édiferenciada em função do risco social e ambiental de cada bairro. A alocação dos agentes com base nas necessidades é importante, pois permite 0 alcance universal, ao mesmo tempo em que garante que populações residentes em áreas de alto risco recebam mais atenção no desenvolvimento dos programas necessários 7,8 .

Para estabelecer o quantitativo de imóveis a serem inspecionados pelos agentes, o Programa $\mathrm{N}$ acional de Controle da Dengue (PNCD) determina que todos os estabelecimentos do município (residências, comércios, prédios públicos, terrenos baldios) sejam trabalhados pelos agentes desaúde com uma periodicidademáxima desessenta dias, o que representa aproximadamente seis visitas a cada imóvel durante 0 ano 9 .

No município de Olinda, existem 157.386 imóveis, segundo os registros do Sistema de Informação de Febre Amarela e Dengue (FAD), 0 que perfaz um total de 944.316 visitas a serem realizadas no ano. Entretanto, esse número, em 2006 , foi de 746.783 , que representa $79 \%$ do esperado. Desta forma, este trabalho teve como objetivo analisar alguns aspectos que poderiam ter interferido no fato de não se ter al cançado o número de imóveis estabelecidos pelo PNCD, dentre eles o número de faltas e a quantidade de imóveis trabalhados por dia pelos AVA. 


\section{M etodologia}

O presente estudo foi realizado no Centro de Vigilância Ambiental de Olinda (CEVAO), onde se criou um banco de dados com a relação de todos os AVA que trabalharam no ano de 2006, considerando o número de faltas de cada agente ao mês, o período que estavam sob licença médica e o mês em que estavam de férias, de forma que se pôde determinar o quantitativo real de agentes em cada mês, conforme a Tabela 1.

Para a análise dos dados referentes à frequência dosAVA eao número de estabelecimentosinspecionados, foram construídas tabelas e gráficos, através de planilhas eletrônicas no Excel, com base na distribuição deagentes ao mêseno número de imóveis trabal hados mensalmente que foram obtidos através de registros do CEVAO.

0 cálculo da "média de imóveis inspecionados por AVA ao dia" foi realizado aplicando-se os valores (mensais) encontrados na Tabela 1 à seguinte fórmula:

$\begin{aligned} & \text { Média deimó- } \\ & \text { veis/AVA/dia }\end{aligned}=\frac{\mathrm{N}^{\circ} \text { imóveis inspecionados }}{\text { por mês }}$

Dessa forma, em cada mês, pode-se determinar a média diária de visitas domiciliares quecada agente de saúdeambiental realizou. A plicando essas médias à fórmula e retirando o item "faltas", foi possível calcular o "número de imóveis/mês que seriam trabalhados, caso os AVA não houvessem faltado" $(X)$ e comparar com o número de imóveis trabalhados em 2006 (Gráfico 1).

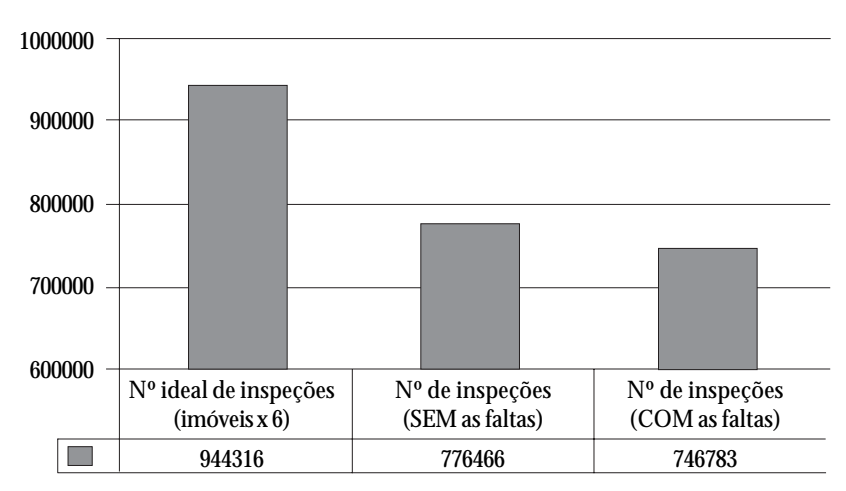

Gráfico 1. Comparativo entre o número de inspeções e a frequência dos Agentes de Vigilância Ambiental no município de Olinda no ano de 2006.

Média de imóveis/AVA/dia $=\frac{X}{\text { Diasúteis } \times n^{\circ} \mathrm{AVA}}$

Em seguida, calculou-se o número esperado de imóveis trabalhados pelos AVA em exercício, descrito como o número de imóveis que seriam trabalhados por mês caso os agentes mantivessem a média estabelecida pelo programa de trinta imóveis inspecionados por dia. Para isso, foi preciso apenas substituir as diferentes médias mensais obtidas em 2006 por trinta.

M édia ideal (30) imóveis/AVA /dia $=\frac{\begin{array}{c}N^{\circ} \text { esperado de imóveis } \\ \text { inspecionados }\end{array}}{\left(\text { dias úteis } \times n^{\circ} \mathrm{AVA}\right) \text { - faltas }}$

Tabela 1. Total de AVA em campo, por mês, no município de Olinda, 2006.

\begin{tabular}{|c|c|c|c|c|c|c|c|c|c|c|c|c|}
\hline & jan & fev & mar & $a b r$ & mai & jun & jul & ago & set & out & nov & dez \\
\hline $\mathrm{N}^{\circ}$ faltas & 62 & 43 & 153 & 94 & 92 & 112 & 105 & 138 & 114 & 113 & 65 & 103 \\
\hline $\mathrm{N}^{\circ}$ AVA contratados & 125 & 125 & 124 & 125 & 124 & 129 & 136 & 137 & 137 & 141 & 143 & 142 \\
\hline $\begin{array}{l}\text { Nimóveis } \\
\text { inspecionados }\end{array}$ & 61.854 & 45.422 & 60.783 & 59.949 & 61.013 & 45.071 & 73.879 & 62.852 & 66.029 & 59.678 & 69.542 & 80.711 \\
\hline $\begin{array}{l}\text { № dias efetivamente } \\
\text { trabalhados }\end{array}$ & 22 & 20 & 23 & 20 & 23 & 22 & 21 & 23 & 21 & 22 & 22 & 21 \\
\hline $\begin{array}{l}N^{\circ} \text { AVA com licença } \\
\text { médica ou INSS }\end{array}$ & 4 & 3 & 3 & 3 & 2 & 3 & 2 & 0 & 0 & 0 & 2 & 1 \\
\hline $\mathrm{N}^{\circ}$ AVA em férias & 14 & 10 & 10 & 9 & 11 & 7 & 11 & 8 & 13 & 13 & 5 & 8 \\
\hline $\begin{array}{l}\text { Total de AVA } \\
\text { trabalhando }\end{array}$ & 107 & 112 & 111 & 113 & 111 & 119 & 123 & 129 & 124 & 128 & 136 & 133 \\
\hline
\end{tabular}


Assim, pôde-se comparar o número de inspeções no ano de 2006 com o número de estabelecimentos que seriam inspecionados, caso os AVA mantivessem uma média de trinta casas por dia (Gráfico 2). Essa comparação permitiu determinar quantas inspeções deixaram de ser realizadas em 2006 pelo fato dos agentes terem mantido uma média abaixo de trinta imóveis/ dia.

A razão para utilizar uma média de trinta imóveis/dia como comparação baseia-se no manual da Fundação Nacional de Saúde, que estabeleceessequantitativo devisitas para cada agente de saúde ambiental.

Outros dados também utilizados neste estudo foram os documentos de comunicação interna do Centro de Vigilância Ambiental, denominados $\mathrm{Cl}$. Esses documentos foram necessários para se avaliar al guns entraves como, por exemplo, as solicitações para os agentes participarem de cursos de capacitação e outras atividades extras demandadas de outras coordenações, além deestarem notificadas a falta de al guns materiais.

\section{Resultados ediscussão}

A primeira comparação que se pode estabelecer foi a relação entre o número de inspeções e as faltas dos AVA. Percebe-se, através do Gráfico 1, que a quantidade de visitas que seriam realizadas, caso os agentes não houvessem faltado, sofreu uma pequena variação quando comparado às visitas realizadas em 2006, contabilizando as faltas dos AVA. Ao longo do ano, a quantidade de inspeções, sem contabilizar as faltas dos AVA

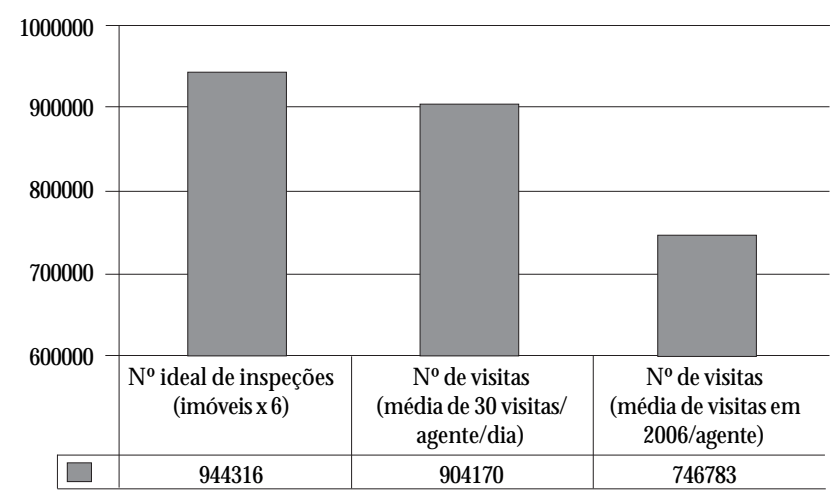

Gráfico 2. Comparativo de inspeções realizadas pelos agentes com média de 30 imóveis/ dia com as médias de 2006.
(776.466) e com as faltas dos mesmos (746.783), representou uma variação de apenas 3,97\% (29.683).

A comparação seguinte se refere ao número de inspeções e às médias diárias de imóveis visitados. O Gráfico 2 mostra que o número de visitas realizadas com uma média diária de trinta imóveis por agente apresenta resultados mais elevados quando comparado com a quantidade de inspeções em 2006, em queapresentaram médias que variavam entre 17,9 e30 imóveis/ agente/ dia (média geral=24,8). No ano de 2006, a diferença dessas médias representaria um aumento considerável de 16,7\% (157.387) no total de inspeções realizadas.

Percebe-se assim que o número de inspeções realizadas pelos AVA por dia teve uma maior influência no baixo rendimento apresentado no ano de 2006, quando comparado ao número de faltas dos agentes. Entretanto, é importante ressaltar que esse percentual de visitas em 2006 poderia apresentar-se com melhores resultados não fossem alguns entraves encontrados no processo de trabal ho dos agentes de vigilância ambiental, que serão analisados no decorrer do trabalho.

Um dos obstáculos encontrados pelos agentes para que esses números tornem-se satisfatórios e alcancem os resultados esperados são os imóveis que estão fechados no momento da visita do agente eaqueles em que o proprietário não permite que se realize o seu trabalho (recusas). Alguns relatórios de acompanhamento do CEVAO mostram que, em alguns locais, é alto 0 número de pendências, variando entre 15 e $25 \%$. Em municípios com infestação domiciliar significativa (normalmente maior do que $5 \%$ ) e em estações do ano favoráveis ao desenvolvimento do vetor, com elevadas temperaturas e chuvas regulares, um índice de pendência (casas fechadas e recusas) em torno de $20 \%$ pode ser suficiente para manter a transmissão de dengue, mesmo que 0 trabalho seja realizado satisfatoriamente nos demais imóveis9.

Ferraz et al.$^{6}$ verificaram em seu trabalho re alizado na cidade do Recife que existem imóveis que não estão recebendo as visitas dos agentes ambientais devido à dificuldade no acesso a alguns imóveis, especialmente prédios de apartamentos, e da ausência de autorização para os agentes ambientais adentrarem em imóveis fechados e terrenos sem edificação. A existência de imóveis sem a cobertura do programa comprometea efetividade das ações dos agentes ambientais nos imóveis vizinhos, poisal gumasáreas com uma cobertura considerada boa pelos ASA po- 
dem continuar a apresentar a ocorrência de agravos, como dengue, além da presença de escorpiões e ratos oriundos desses imóveis aos quais os agentes não têm acesso.

É necessário que estratégias sejam criadas para, além de garantir a atuação dos agentes em imóveis fechados e de difícil acesso, diminuir o número de recusas às visitas domiciliares, que muitas vezes são devido ao medo dos moradores abrirem a porta de suas casas para uma pessoa estranha. Alguns autores ${ }^{5}$ recomendam que uma carta de apresentação feita pela Vigilância Ambiental com nome completo do AVA, o objetivo da visita e os telefones da unidade seja entre gue aos moradores, conscientizando-os da importância das ações desenvolvidas pelos agentes e reduzindo sua insegurança quanto ao acesso a seus domicílios. Ações educativase parcerias com outros atores sociais, tais como escolas, igrejas, sociedade civil organizada emídia, buscando envolvê-los na divulgação do programa, teriam um grande impacto na redução do número de recusas das visitas nos domicílios.

Outro problema encontrado como barreira ao desenvolvimento do trabalho dos AVA éa falta de materiais. Os documentos de comunicação interna do CEVAO mostram que são frequentes os pedidos por planilhas, pranchetas, canetas, fardamento, dentre outros, e que levam tempo para chegarem ao seu destino, o que prejudica o desempenho dos agentes e se reflete na quantidadedeimóveis visitadosena qualidade das ações prestadas à população. Os materiais utilizados nas ações do programa não têm sido disponibilizados em tempo hábil, prejudicando o trabalho dos ASA, que deixam de realizar as atividades previstas no ciclo de visitas. Dentre os materiais que faltam estão raticida, inseticida, equipamento de proteção individual, kit para avaliação da água, fardamento e material educativo $0^{6}$.

É preciso identificar os motivos dos atrasos das licitações e buscar estratégias para que as aquisições de materiais ocorram em prazos adequados. A distribuição e abastecimento de insumos, equipamentos e instrumentos necessários na execução das atividades de campo são degrande importância para o correto andamento das ações eempecil hos dessa natureza repercutem no desempenho do trabalho prestado pelos AVA à comunidade, podendo refletir em um número de visitas domiciliares abaixo do esperado.

Em trabal ho realizado por Albuquerque ${ }^{10}$, no qual entrevistou vários agentes de saúde ambiental do Distrito Sanitário III no município de Recife, foram constatados outros problemas que dificultam o processo de trabalho dos agentes relacionados aos precários vínculos empregatíciosque se dão principalmente por contrato temporário. Segundo a autora, essa situação gera, na grande maioria dos agentes, um sentimento de insegurança que enfraquece o seu compromisso com a vigilância e, principalmente, com a população.

Uma constatação dessa fraca relação dos agentes com a vigilância ambiental encontra-se no estudo realizado por Ferraz et al. ${ }^{6}$ na cidade do Recife, em queéestabelecido um ciclo de quarenta dias, e observou-se que nem todos os imóveis são visitados dentro desseperíodo, onde $58 \%$ dos ASA declararam que realizam "às vezes" as visitas dentro do ciclo de quarenta dias e $21 \%$ declararam que "não" realizam dentro do ciclo.

A frágil estabilidade no emprego também proporciona uma rotati vidade não desejada desses profissionais nas áreas, prejudicando o andamento do Programa de Saúde Ambiental, seja pelas áreas que ficam descobertas, seja pela sobrecarga de trabal ho que al guns agentes são obrigados a assumir. Essa rotatividade é constatada no CEVAO através do banco criado para realização deste estudo, em que se viu a dispensa de onze agentes, a maioria deles devido à grande quantidade de faltas e seu descompromisso com o trabalho, e a contratação de outros 28 , ao longo do ano de 2006.

O grandenúmero de solicitações para realização de outras ações de saúdee cursos de capacitação faz com que os AVA diminuam sua produção mensal devisitas domiciliares. As solicitações são constantes no CEVAO por seus profissionais de vigilância ambiental, principalmenteentreosmeses de agosto e novembro de 2006. Esse fato é evidente ao se comparar, na Tabela 1, o número de agentes no mês e a quantidade deimóveis visitados, em que, por exemplo, no mês de julho, no qual havia 123 profissionais trabalhando, foram visitados 73.879 imóveis; já no mês denovembro, no qual havia 136 profissionais, a quantidade de imóveis visitados foi menor (69.542).

A elaboração de relatórios periódicos (mensais) das atividades dos agentes em sua área de atuação sobre sua produtividade é de grande importância e urgente, a fim de identificar e cobrar resultados daqueles quenão apresentam um rendimento satisfatório ao longo dos meses. $\mathrm{Re}$ latórios a respeito da quantidade deagentes contratados, afastados por licença médica ou de férias servirão também para organizar a liberação de AVA para capacitação, quando solicitados por outros programas e ações específicas. 


\section{Conclusão}

Através do que foi exposto, percebe-se que 0 Centro de Vigilância Ambiental de Olinda apresenta alguns entraves que exigem mudanças a respeito do processo e condições de trabal ho dos AVA no sentido de promover reajustes e inovações importantes.

É preciso que a vigilância ambiental ofereça os recursos materiais necessários para que os agentes possam desempenhar seu papel de forma satisfatória e incentive-os quanto a sua im-

\section{Colaboradores}

PC Albuquerque participou da análise dos dados, discussão dos resultados, correção e aprovação da versão a ser publicada; FC Pimentel e RML Acioli participaram da concepção da pesquisa, coleta de dados, metodologia, análise, revisão da literatura, discussão dos resultados e redação do artigo.

\section{Referências}

1. Barcellosa C, Quitério LAD. Vigilância ambiental em saúde e sua implantação no Sistema Único de Saúde. Rev. Saúde Pública 2006; 1(40):170-177.

2. Brasil. Ministério da Saúde. Sistema Nacional de Vigilância Ambiental em Saúde. Brasília: Fundação Nacional da Saúde; 2001.

3. Brasil. Fundação Nacional de Saúde. Vigilância ambiental em saúde/Fundação $\mathrm{N}$ acional de Saúde. Brasília: FUNASA; 2002.

4. Brasil. Lei $n=11.350$ de 5 de outubro de 2006. Regulamenta o § 50 do art. 198 da Constituição, dispõe sobre 0 aproveitamento de pessoal amparado pelo parágrafo único do art. 20 da Emenda Constitucional $n$ ㅇ 51, de 14 de fevereiro de 2006, e dá outras providências. Diário Oficial da União 2006; 6 out.

5. Prefeitura de Cuiabá. Combate à Dengue em Cuiabá ultrapassa média nacional de efetividade em vistoria. 2007. [acessado 2007 mai 19] Disponível em: http:// www.cuiaba.mt.gov.br/noticias.jsp?id noticia $=5128$

6. Ferraz JAR, Matos JM O, Leal M AP, Falcão NCB. Relatório preliminar consolidado de auditoria de natureza operacional - avaliação do programa de saúde ambiental - PSA. Recife: Secretaria Municipal de Saúde; 2005. portância na transformação da realidade local pela qual são responsáveis, identificando, prevenindo, eliminando ou minimizando os riscos de transmissão de doenças e outros agravos à saúde da população provenientes do ambiente.

Além disso, sugere-se que avaliações mais criteriosas e constantes das atividades dos AVA sejam realizadas, no sentido de identificar e corrigir faIhas no seu processo de trabalho, para que assim seja possível aumentar o número deinspeções domiciliares eatingir as metas predeterminadas pelo Programa Nacional de Controle da D engue.
7. Lyra TEM . 0 exército da limpeza. Recife: Secretaria Municipal de Saúde; 2003.

8. Nelson D. Um batalhão de agentes da Prefeitura se distribui pelos bairros do Recife para combater os fatores ambientais de risco à saúde. Programa de Saúde Ambiental do Recife. [acessado 2007 mai 19] Disponível em: http://inovando.fgvsp.br/conteudo/documentos/ 20experiencias2003/PERNAM BU CO-SaudeAmbiental. pdf

9. Brasil. M inistério da Saúde. Fundação Nacional de Saúde. Programa Nacional de Controle da Dengue. Suporte legal às ações de campo. Brasília: M inistério da Saúde; 2002.

10. Albuquerque KM. Saúde e ambiente no nível local: avaliação das ações do Agente de Saúde Ambiental (ASA), na cidade do Recife - PE [dissertação]. Recife $(P E)$ : Centro de Pesquisas Aggeu Magalhães, Fundação Oswaldo Cruz; 2005.

Artigo apresentado em 01/10/2007

Aprovado em 31/03/2008 